\title{
Seismic events miss important grain-scale mechanisms governed by kinematics during shear failure of porous rock
}

\author{
Alexis Cartwright-Taylor ( $\nabla$ alexis.cartwright-taylor@ed.ac.uk ) \\ University of Edinburgh https://orcid.org/0000-0001-7805-4576 \\ Maria-Daphne Mangriotis \\ University of Edinburgh
}

lan Main

University of Edinburgh

lan B. Butler

University of Edinburgh

Florian Fusseis

University of Edinburgh

Martin Ling

Edinburgh Hacklab

Edward Ando

Univ. Grenoble Alpes, CNRS, Grenoble INP, 3SR, Grenoble https://orcid.org/0000-0001-5509-5287

Andrew Curtis

University of Edinburgh

Andrew Bell

University of Edinburgh https://orcid.org/0000-0002-5633-6289

\section{Alyssa Crippen}

University of Edinburgh

Roberto Rizzo

University of Edinburgh

Sina Marti

University of Edinburgh

Derek Leung

University of Edinburgh

Oxana Magdysyuk

Diamond Light Source https://orcid.org/0000-0003-3842-3239 
Keywords: micro-seismic events, kinematics, catastrophic failure

Posted Date: November 4th, 2021

DOI: https://doi.org/10.21203/rs.3.rs-1034813/v1

License: (c) (1) This work is licensed under a Creative Commons Attribution 4.0 International License. Read Full License

Version of Record: A version of this preprint was published at Nature Communications on October 18th, 2022. See the published version at https://doi.org/10.1038/s41467-022-33855-z. 


\section{Seismic events miss important grain-scale mechanisms governed by kinematics} during shear failure of porous rock

A. Cartwright-Taylor ${ }^{1 *}$, M.-D. Mangriotis ${ }^{1}$, I. G. Main 1 , I. B. Butler ${ }^{1}$, F. Fusseis ${ }^{1}$, M. Ling ${ }^{2}$, E. Andò ${ }^{3}$,

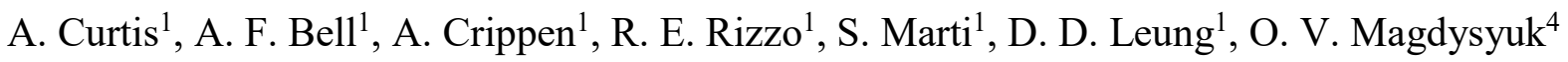

\section{Affiliations}

${ }^{1}$ School of GeoSciences, University of Edinburgh, Edinburgh, UK.

${ }^{2}$ Independent Electronics Developer, Edinburgh Hacklab, Edinburgh, UK.

${ }^{3}$ Laboratoire 3SR, Université Grenoble Alpes, Grenoble, France.

${ }^{4}$ Beamline I12-JEEP, Diamond Light Source, Didcot, UK.

*Correspondence to: alexis.cartwright-taylor@ed.ac.uk 
miss important kinematically-governed grain-scale mechanisms prior to and during shear failure. Contrary to common assumption, we find seismic amplitude is not correlated with local imaged strain; large local strain often occurs with small acoustic emissions, and vice versa. Local strain is

predominantly aseismic, explained in part by grain/crack rotation along an emergent shear zone, and the shear fracture energy calculated from local dilation and shear strain on the fault is half of that inferred from the bulk deformation. This improvement in process-based understanding holds out the prospect of reducing systematic errors in forecasting system-sized catastrophic failure in a variety of applications.

\section{Main Text}

Catastrophic failure of porous materials is important for wide range of applications and on a variety of scales, from natural and induced earthquakes to the failure of synthetic materials and engineered structures. Understanding the micro-structural processes that operate during weakening and failure of these materials, and the associated strain partition between seismic and aseismic components, is a critical barrier to reducing the significant uncertainties involved in inferring local deformation and strain rates from remotely accessed field-scale seismic or geodetic data. Without this ability, we are unable to improve methods for forecasting and mitigating the risks associated with catastrophic failure.

The key driving mechanism of catastrophic failure under compression is the concentration of precursory damage along localised zones of deformation, eventually resulting in system-sized failure along a distinct and emergent sub-planar discontinuity (1). Mean field models explain some aspects of the observed behaviour, but rely on average properties that cannot account for localisation or the detailed micro-mechanics (2). They are often derived solely from the properties of recorded acoustic emissions (AE), which are assumed to be representative of the local strain, and cannot account for local aseismic mechanisms that typically constitute $>99 \%$ (3) of the total accumulated strain energy. The 
partition between seismic and aseismic strain directly constrains the rheology and the detectability of seismic precursors to failure, and is currently the largest source of uncertainty in operational forecasting of seismic risk from subsurface engineering projects (4). However, we have limited constraints on its evolution at a large scale, and none at the microscopic scale.

The size, location and fracture mode of individual micro-cracking events are commonly inferred from AE waveforms, sometimes calibrated against thin sections that reveal the microscopic processes destructively after the test. These processes include elastic compaction, pore collapse, and the development of small tensile micro-cracks oriented parallel to the maximum principal stress $(1,5,6)$. Cracking is a form of local failure either due to locally weaker material or local stress concentrations resulting from changes in geometry (7-11). Under a constant deformation rate, the peak stress often coincides with the onset of an extremely rapid, non-linear acceleration of $\mathrm{AE}$ event rate $(5,12)$, resulting in violent, abrupt failure and rapid stress drop. The non-linear rheology and short time scales $(<40 \mathrm{~s}$ in Clashach sandstone; Supplementary Figure 3) make the micro-mechanisms involved in the transition from stable crack nucleation along a localised shear zone to system-sized rupture extremely difficult to capture and characterize in real time. However, failure can be extended in duration by controlling the loading rate to maintain a constant $\mathrm{AE}$ event rate $(1,13,14)$. This procedure prevents the acceleration of crack damage and can extend to minutes or even hours the microscopic processes that usually occur over a few seconds, enabling the post-peak-stress region to be studied under quasistatic conditions. Mapping AE source locations during such an experiment provided the first in-situ view of crack localisation and shear zone growth, and an estimate of the associated shear fracture energy, a key parameter in the mechanics of earthquakes and faulting $(1,13)$.

More recently, in-situ high-energy x-ray micro-tomography $(\mu \mathrm{CT})$ time-lapse imaging of rock deformation experiments has enabled the non-destructive characterization of microstructural damage and local strains (15-17). Such studies have so far been limited to constant strain rate experiments 
where changes after peak stress occur too rapidly to be captured, even with the high-speed imaging capabilities of a synchrotron. Here, we address this research gap by presenting detailed in-situ images of rock failure obtained during experiments in a novel x-ray transparent triaxial deformation cell (see Methods), which for the first time integrates acoustic monitoring with fast time-lapse synchrotron x-ray imaging, on the beamline I12-JEEP (18) at the Diamond Light Source, UK. We slowed down failure using feedback from the AE event rate (see (1) and Supplementary Note), extended the failure time from $\sim 1$ minute to $\sim 50$ minutes (Supplementary Figure 3), and captured sample weakening and failure in a series of eighteen 3D x-ray $\mu \mathrm{CT}$ volumes (Fig. 1a), along with the locations and amplitudes of the AE sources. This allowed us to unlock the relationship between the seismic sources, the local strain and the associated underlying micro-mechanisms. We find that AE miss important developments on the grain scale; early strain localisation does not necessarily lock the system in; and the micro-mechanics on the grain scale are governed by kinematics, in turn governed by the rock configuration.

\section{Micro-mechanics of strain localisation and failure from in-situ x-ray images}

Under AE-controlled quasi-static loading, the sample eventually experienced system- sized brittle failure along a localised shear zone (Fig. 1), with x-ray $\mu \mathrm{CT}$ volumes of the precursory microscale processes obtained at the times indicated. The details of damage localisation and shear zone development are shown in post-yield 2D $\mu \mathrm{CT}$ slices (Fig. 2) and incremental 3D strain fields obtained by Digital Volume Correlation (Fig. 3).

AE activity preceded initial strain localisation during early loading [stage (i) in Fig. 1; Fig. 3 first panel], consistent with previous AE studies on porous rocks using much larger samples $(5,6,19)$ or in-situ $\mu \mathrm{CT}$ imaging of smaller samples $(20,21)$. Between yield and shortly after peak stress [stage (ii); Fig. 3 panels a-b], the spatial distribution of shear strain closely followed that of dilation, and competing strain clusters localised along three distinct conjugate planes of similar amplitude and dip 
$94 \quad\left(30^{\circ}\right.$ to maximum principal stress; typical of optimally-oriented faults in nature) but variable strike, 95 indicating self-organised exploration of candidate shear zones. These direct observations highlight the 96 exploratory nature of emergent localisation in a complex system.

In stage (iii), dilation and shear strain concentrated along the critically-oriented shear zone soon after peak stress (Fig. 3 panel c), initially with a brief hiatus in the damage rate (Supplementary Figure 4). The shear zone emerged spontaneously from the self-organised localisation of numerous, narrow en-echelon tensile microcracks, which nucleated simultaneously along the whole length of the shear zone (Fig. 2b and c; slice c) as the upper part of the sample moved as one continuum relative to the lower part. These cracks, which mainly crossed a single whole grain, nucleated at pore edges, at grain contacts where Hertzian stresses accumulated within force chains, and as wing cracks at the tips of sliding grain boundary cracks (consistent with 7-11). As damage mechanisms localised increasingly on the shear zone, initial diffuse compaction in the bulk was swamped by localised dilation and shear strain (Supplementary Figure 6; Supplementary Movies 3-8) as a fat tail emerged in their respective frequency-amplitude distributions, which eventually became bimodal (Supplementary Figure 5).

In stage (iv), dilation and shear strain were highly correlated in the shear zone (Fig. 3), consistent with several mechanisms accommodating bulk shear motion (Fig. 2c; slices c-f). These included en-echelon, tensile cracks nucleating and widening to produce extension and volumetric strain; aseismic rotation of tensile cracks associated with neighboring grain rotation, which prevented tensile crack propagation and supported the walls of the shear zone to maintain finite grain-size thickness throughout failure; and sliding on favourably- and unfavourably-oriented cracks, including some resembling Riedel shear zones. Grain fragmentation generated a proto-cataclasite within the shear zone as whole grains disintegrated, partial grains fractured off the shear zone walls, and fractured grains filled cavities (Fig. 2c; slices d-g). These observations highlight the significant contribution of 
aseismic mechanisms (i.e., rotation) to the overall failure process, relative to seismic mechanisms (i.e., cracking, stick-slip sliding; б).

Eventually coherent slip occurred on a contiguous fault 'plane' that reached the sample

\section{AE location and the seismic strain partition factor}

We recorded $\sim 3600$ AE events above ambient noise, some $5 \%$ of which were selected using objective criteria for location analysis (see Methods). The most likely location for each event was inferred by constraining it to the maximum local strain within a kinematically-derived hyperboloid of possible locations (see Methods and Supplementary Figure 11). The same unique location was found for $85 \%$ of the located AE events in both the dilation and shear strain fields due to the high correlation between the two strain fields. Even with the maximum strain constraint, the largest AE events did not occur at locations of high local strain (Fig. 4 solid black ellipses), implying the seismic strain partition coefficient is highly variable in space. Many small events occurred in regions of high local strain (Fig. 
4 dashed black ellipses), consistent with deformation being primarily aseismic in the shear zone, while many large events occurred in regions of low local strain in the bulk (Fig. 4 and Supplementary Figure 12). Dilation and shear strain are positively correlated over the whole experiment, but this positive correlation is much stronger at the AE locations (Supplementary Figure 13), consistent with the large mixed mode component of seismic moment tensors observed in $(6)$.

We inferred a seismic strain partition coefficient for bulk deformation of $0.2 \%$ from summing the inferred scalar seismic moments (see Methods), verifying that deformation is primarily aseismic. This is much lower than the $1 \%$ inferred by (3), most likely due to using a less brittle material (sandstone) under quasi-static rather than constant strain rate loading. Both estimates are a lower bound due to the finite signal to noise ratio.

\section{Rupture energy}

The shear fracture energy or energy release rate, $G_{c}$, is a crucial parameter for modelling shear fracture propagation (23). It is the energy required per unit area for breakdown processes, such as tensile fracturing, to create the new fault surface. It characterises the strain-softening region of the stress-strain curve and is conventionally estimated from bulk axial stress and strain data (Fig. 5a). Here we estimate $\mathrm{G}_{\mathrm{c}}$ both from bulk and from knowledge of the local strain in the shear zone (see Methods), finding that bulk estimates are biased to large values.

We computed $\mathrm{G}_{\mathrm{c}}$ (Fig. 5c) by integrating the shear stress versus fault slip record (Fig. 5b) for (i) uniform slip on a sample-sized fault from bulk axial stress and strain (as in 24), (ii) uniform slip from bulk axial stress and strain at each $\mu \mathrm{CT}$ scan time, and (iii) total observed local slip measured directly from local dilation and shear strains within the shear zone. We observed a smaller critical slip distance, $\Delta \mathrm{u}^{*}$ (Fig. 5a) for local slip $(0.14 \mathrm{~mm})$ than for uniform slip $(0.2 \mathrm{~mm})$, while the integrated curves 
yielded $\mathrm{G}_{\mathrm{c}-\mathrm{i}}=5.06 \mathrm{~kJ} / \mathrm{m}^{2}, \mathrm{G}_{\mathrm{c}-\mathrm{ii}}=3.72 \mathrm{~kJ} / \mathrm{m}^{2}$ and $\mathrm{G}_{\mathrm{c}-\mathrm{iii}}=2.53 \mathrm{~kJ} / \mathrm{m}^{2}$, where dilation and shear strains contributed $36 \%$ and $64 \%$ of $\mathrm{G}_{\mathrm{c}-\mathrm{iii}}$ respectively. The discrepancy between $\mathrm{G}_{\mathrm{c}-\mathrm{i}}$ and $\mathrm{G}_{\mathrm{c}-\mathrm{i}}$ arises from the feedback control: many of the $\mu \mathrm{CT}$ scan times after peak stress coincided with a reduction in stress and strain as the ram backed off to maintain the AE event rate (Fig. 1a). However, local shear fracture energy, $\mathrm{G}_{\mathrm{c}-\mathrm{iii}}$, is only $0.68 \mathrm{G}_{\mathrm{c}-\mathrm{i}}$ and $0.5 \mathrm{G}_{\mathrm{c}-\mathrm{i}}$. Hence, bulk estimates of $\mathrm{G}_{\mathrm{c}}$ for uniform slip across a samplesized fault can significantly exceed those determined directly from local slip measurements in the developing shear zone.

\section{Comparison with laboratory observations of shear failure}

The evolving shear zone imaged in the 3D x-ray volumes and strain fields validates many inferences from classic AE experiments, such as the nucleation and growth of a shear zone containing the eventual fault plane due to the spontaneous localisation of en-echelon tensile microcracks $(1,13)$. These data also provide new insight into the micro-mechanics of strain localisation and shear failure, notably: the grain size control on failure; the self-organised exploration of candidate shear zones close to peak stress; the continued correlation between dilation and shear strain throughout sample weakening; the relative importance of aseismic mechanisms such as crack rotation in accommodating bulk shear deformation; the lack of correlation between locations of large seismic events and regions of high local strain; the very low and locally highly variable seismic strain partition coefficient; and the relatively low local shear fracture energy compared to bulk estimates.

The strong correlation between local dilation and shear strain is consistent with in-situ $\mu \mathrm{CT}$ observations up to peak stress (16). Here, we show that this correlation continues throughout quasistatic failure, confirming, at higher resolution, inferences from seismic velocity tomography (25). If volumetric strain is a proxy for tensile cracking, the correlation confirms the existence of a cohesive zone, but with crack damage distributed throughout the shear zone rather than concentrated solely in a 
breakdown zone at the propagating front of a pre-existing discontinuity, as proposed by Barenblatt (26). This observation is consistent with the fact that no contiguous fault exists until very late in the process, and even then cracking continues to occur at the grain scale by fracturing individual grains and breaking remaining grain-scale asperities distributed across the whole shear zone.

The Gutenberg-Richter $b$-value estimate from the AE was $1.94 \pm 0.04$ (Supplementary Figure 10), slightly higher than $b \sim 1.7$ estimated for granite under similar loading conditions (1). Both are likely high due to the forced quasi-static failure protocol. When $b>1.5$, the moment release is dominated by smaller events, so our very low estimate for the seismic strain partition factor $(0.2 \%)$ may be due in part to the lack of detection of smaller events above the relatively high ambient noise present in the synchrotron beamline. However, this does not explain the relative absence of large AE events in high strain regions. The distribution of AE locations reflects the high $b$-value, with many moderate/small events occurring in regions of large directly measured strain. One explanation could be that the reduction in local stiffness with increasing damage leads to the preference for smaller events along the shear zone, with fewer but larger AE occurring at locally stiff regions off-fault where strain energy accumulates with relatively little deformation. These results show that the seismic strain partition coefficient is highly variable locally and therefore the AE source amplitude is not necessarily representative of the local strain. This is consistent with similar counterintuitive scaling shown between avalanche size (related to strain) and average energy (related to AE amplitude) in a local load sharing fibre bundle model (27). These findings may help to explain similar spatial variability inferred at field scale and constrain model uncertainty when forecasting seismic risk (4).

Our estimates of $\mathrm{G}_{\mathrm{c}}$ are close to that estimated for Berea sandstone under the same assumptions (13), and an order of magnitude smaller than reported for granite $(1,24,25)$. Since $\mathrm{G}_{\mathrm{c}-\mathrm{iii}}$ (for local slip in a propagating shear zone) is only $50-68 \%$ of $\mathrm{G}_{\mathrm{c}}$ for uniform slip on a sample-sized fault, significant additional work $(\sim 32-50 \%)$ must be done in the rest of the sample. However, the average off-fault to 
on-fault incremental shear and volumetric strain ratios during failure are only $9 \%$ and $3 \%$ respectively (Supplementary Table 1), consistent with ratios of off-fault dissipated energy to on-fault shear fracture energy in granite (25). The remaining $20-38 \%$ of additional work must be accommodated by aseismic mechanisms within the shear zone (i.e., crack and grain rotation and silent grain rearrangement). Slip due to rotation for individual cracks can be as large as $77 \pm 29 \%$ of the local relative slip (Supplementary Table 2), and hence likely accounts for a significant proportion of the shear fracture energy.

\section{Relating micro-mechanics with natural slip systems and tectonic-scale kinematics}

Our results highlight the complexity of damage processes occurring within shear zones during localisation and through weakening and failure. Local crack rotation with antithetic slip (Fig 2c-iii) offers an additional mechanism for local stress rotation and slip on unfavourably-orientated faults without the need for high pore pressure (28). It may also help to explain observations of interlaced orthogonal faults and accompanying geometric complexities (such as en-echelon faulting, aftershock migration and event triggering from one orientation to another) in the 2019 Ridgecrest earthquake sequence and other examples (29), by providing alternative pathways along which to accommodate strain during a cascading rupture process.

Our observations of crack rotation provide experimental evidence to support models of tectonic kinematics (e.g., 30-33), which postulate that rotation in rifting margins and strike-slip settings can emerge as a result of local strength heterogeneity in the crust. In these cases, a strong 'fixed' zone (in our case, the rock matrix between en-echelon tensile microcracks) transmits the bulk drag, preventing pure shear and enabling extension and rotation, with rotation facilitated by the surrounding mechanically weak regions (in our case, the tensile cracks themselves) that accommodate the rotationinduced deformation. The rotation in our experiments is driven by shearing oblique to the en-echelon 
tensile cracks, whereby the strong grain segments transmit the shearing motion and prevent tensile crack propagation beyond a single grain, thereby limiting the width of the shear zone to the grain scale. Crack coalescence eventually occurs by grain fragmentation within the shear zone and by the breaking of asperities, forming strands of connected crack porosity aligned along the shear zone in patterns consistent with dynamic shear failure (34), coalescence of en-echelon rift segments (35) and kink band development in granodiorite (36). The potential for slip along either and/or both surfaces of the shear zone, as well as planes within the shear zone, is also found on a larger scale in nature (37).

This discussion highlights the potential for re-examination of the microstructures and inferred mechanisms associated with larger-scale seismic and aseismic processes in light of the results presented here, in particular the conclusion that seismic events miss important grain-scale mechanisms governed by kinematics before and during shear failure. This improvement in process-based understanding holds out the prospect of reducing systematic errors in forecasting system-sized catastrophic failure in a variety of applications.

\section{Methods}

For a description of how we implemented the AE feedback control of deformation, see the Supplementary Note.

\section{$\underline{\text { Experimental material }}$}

A Permian aeolian sandstone (Clashach) was chosen as the experimental material. Clashach is a quartzrich arenite composed of $>92 \%$ quartz grains, $<8 \% \mathrm{~K}$-feldspar and subordinate lithics. It is well-sorted with fine to medium-sized grains $0.25-0.4 \mathrm{~mm}$ in diameter (38). A highly cemented Clashach sample was used (17\% porosity), which behaved in a mechanically brittle manner when loaded to failure at shallow crustal pressures, and emitted sufficient acoustic emissions for feedback control. Cylindrical 
cores were obtained using a diamond core drill and the ends of the cores were ground flat and parallel on a lathe.

\section{Experimental equipment}

The experiment used our lightweight $(3.5 \mathrm{~kg})$ x-ray transparent triaxial deformation apparatus, Stór Mjölnir (Supplementary Figure 1), developed at the University of Edinburgh. Named after Thor's hammer in Norse mythology, it is an up-scaled version of our miniature triaxial cell, Mjölnir (39), with the addition of a linear variable displacement transducer (LVDT) to measure axial displacement, and two piezoelectric 'Glaser-type' transducers, positioned axially (Supplementary Figure 1), to passively detect acoustic emissions (AE) and actively monitor ultrasonic velocities. These sensors (signal in Volts proportional to the true normal displacement, $u$, of the received elastic wave) were connected to an Applied Seismology Consulting Ltd (ASC) micro-seismic monitoring system by means of two ASC pre-amplifiers. This allowed us to capture AE waveforms and conduct ultrasonic velocity surveys throughout the experiment. Stór Mjölnir is constructed of grade 5 titanium alloy, with an x-ray “transparent" pressure vessel made of 7068-T6 aluminium alloy. It accommodates cylindrical samples of $10 \mathrm{~mm}$ diameter and $25 \mathrm{~mm}$ length and can attain confining pressures up to $50 \mathrm{MPa}$ and apply axial stresses up to $500 \mathrm{MPa}$. It was installed on the x-ray microtomography rotation stage in Experimental Hutch 1 (EH1) of beamline I12-JEEP at the Diamond Light Source.

\section{Experimental protocol}

The experiment was conducted at ambient temperature. The Clashach core was jacketed in silicone tubing and sealed between the pistons within the pressure vessel (Supplementary Figure 1). An effective pressure $\left(\mathrm{P}_{\text {eff }}\right)$ was applied and maintained at $20 \mathrm{MPa}$ throughout the test (confining pressure $\mathrm{P}_{\mathrm{c}}=25 \mathrm{MPa}$ and pore fluid pressure $\mathrm{P}_{\mathrm{p}}=5 \mathrm{MPa}$, where $\mathrm{P}_{\mathrm{eff}}=\mathrm{P}_{\mathrm{c}}-\mathrm{P}_{\mathrm{p}}$. A hydrostatic starting pressure condition (zero differential stress) was achieved by simultaneously increasing the axial pressure to match the confining pressure. Tomographic reference scans were acquired before pressurisation and 
again prior to loading (at zero differential stress) to obtain the initial state of the sample. Two scans were acquired at zero differential stress to characterize the error in the digital volume correlation by correlating two volumes in which the state of the sample was identical (Supplementary Figure 7).

After the initial scans, the sample was loaded continuously at a constant deformation rate of $10^{-5}$ $\mathrm{s}^{-1}$ until the desired AE event rate (1 event/s) was reached, at which point loading at this constant AE rate took over. This protocol extended the failure time from $\sim 1$ minute to 50 minutes, equivalent to an average bulk strain rate of $10^{-7} \mathrm{~s}^{-1}$, sufficient to capture 18 high-quality $\mu \mathrm{CT}$ volumes after peak stress. The sample underwent triaxial deformation to failure evident from a rollover at peak differential stress followed by a gentle decrease in stress ending in an almost constant stress on completion of loading (Fig. 1a and Supplementary Figure 3).

Imaging the deformation in-situ on beamline I12-JEEP (18) was achieved with a $53 \mathrm{keV}$ monochromatic beam detected by a PCO.edge light sensor with I12 in-house optical module of $7.91 \mathrm{x}$ $7.91 \mu \mathrm{m} /$ pixel resolution and $20 \mathrm{~mm} \times 12 \mathrm{~mm}$ field of view. Tomographic volumes of the whole sample, comprising two discrete overlapping scans of the top and bottom of the sample, with vertical translation in between, were acquired every $85 \mathrm{~s}$ throughout the experiment. Individual scans were acquired in approx. 40 seconds and consisted of 1800 projections with a $0.0035 \mathrm{~s}$ exposure time. At each end of the sample, $0.2 \mathrm{~mm}$ (next to the piston) was not captured due to limits on the x-ray field of view, which had a vertical dimension of $12 \mathrm{~mm}$.

Ultrasonic velocity surveys were conducted every 5 minutes and acoustic emissions monitored continuously throughout the experiment, along with actuator pressure and axial displacement, confining pressure, and pore fluid pressure and volume.

\section{$\underline{\text { Tomographic reconstruction }}$}


The tomographic dataset was fully reconstructed on the Diamond cluster using the framework SAVU (40) with automatic centre detection (41), ring removal (42) and distortion correction (43), a Paganin phase filter with delta/beta ratio of $0.6(44)$ and a 2D GPU-accelerated filtered backprojection ('FBP_CUDA') reconstruction algorithm using the integrated ASTRA toolbox (45-48). This yielded 16-bit image volumes of $2560 \times 2560 \times 1800$ voxels, with a voxel size of $7.91 \times 7.91 \times 7.91 \mu \mathrm{m}^{3}$. Each pair of reconstructed volumes comprising both ends of the sample, acquired with an overlapping region of 520 vertical pixels $(4 \mathrm{~mm})$, was merged together using digital volume correlation (DVC) to match the overlapping ends and generate a time-series of tomographic volumes of the full sample (orange dots in Fig. 1 and blue dots in Supplementary Figure 3).

\section{Estimation of bulk stress and strain}

Axial displacement was converted to axial strain, $\varepsilon$, which was then corrected for rig stiffness, $\mathrm{k}_{\text {rig }}$ to obtain the axial sample strain, $\epsilon$, as follows: $\epsilon=\varepsilon / \sigma-\sigma\left(1 / \mathrm{k}_{\text {rig }}\right)$. Differential stress, $\sigma$, on the sample was obtained from $\sigma=\sigma_{1}-\sigma_{3}$, where $\sigma_{1}$ is the axial stress, equal to the load, $F$, on the sample (obtained from a calibration of the measured ram pressure with a load cell) divided by the surface area, A, of the sample end $\left(\sigma_{1}=\mathrm{F} / \mathrm{A}\right)$, and $\sigma_{3}=\mathrm{P}_{\text {eff. }}$

\section{Dynamic wave velocity estimation}

Changes in ultrasonic compressional-wave velocity were measured by means of the pulse transmission technique (49) between the pair of AE transducers, with source-receiver geometries at opposite ends of the sample (Supplementary Figures 1 and 11). Velocity surveys were conducted by the ASC Pulser Interface Unit at constant time intervals (5 minutes) during the experiment. A pulse of acoustic energy was sent through the sample from each transducer in turn and its arrival at the other sensor was recorded. To understand the system delay (including travel-time through pistons) a seismic test using the pistons without any sample in between them was recorded, and the difference in time between pulse onset at the origin and pulse onset retrieval at the other piston was calculated as the time-correction. 
Detected AE signals were amplified and sent to the two-channel monitoring system, which recorded the full event waveforms, including arrival time, amplitude and first-motion information. The preamplification and trigger threshold (based on an instantaneous amplitude) were set at $70 \mathrm{~dB}$ and 280 $\mathrm{mV}$ respectively, with the aim of controlling the AE event rate effectively. The gain was determined from a benchmark pencil lead-break test in the laboratory prior to visiting the synchrotron, and the trigger threshold was determined by the ambient noise in the experimental hutch on the I12-JEEP beamline. AE event rates were calculated from the number of events recorded in each $10 \mathrm{~s}$ time window. AE amplitudes as a function of time, AE event rate and frequency-magnitude distributions are shown in Supplementary Figure 10.

We interrogated the AE events to obtain a sub-set of the most reliable events for location analysis, ensuring that: (i) individual events were represented in both sensors' recordings, (ii) the AE waveforms satisfied a minimum Signal to Noise Ratio (SNR), (iii) the relative time-delay for a specific AE recorded at the two sensors was robust against noise and yielded a depth uncertainty less than 1 pixel, (iv) the maximum relative time-delay for a specific AE recorded at the two sensors obeyed physical limits given sample dimensions/velocity. The relative time-delays between top and bottom sensor were estimated by cross-correlation of the top and bottom waveforms. Given the limitation of only two sensors at the opposite ends of the rock sample, the experimental geometry led to inherent ambiguity in AE location. However, the specific relative time-delay of an AE event, and knowledge of the dynamic velocity allowed us to define a circular hyperboloid, which marks a 3D surface of constant relative time-delay (Supplementary Figure 11) and therefore a kinematic constraint for AE location.

Using the AE events that passed the selection criteria ( $5 \%$ of 3600 events) we defined each hyperboloid as the locus of potential elementary volumes (with thickness $=1$ pixel) for the $\mathrm{AE}$ location. Time-binning of AE relative to the occurrence of the two scans used to obtain a particular 
strain increment from the DVC permitted comparison of AE with the local incremental strains.

Assuming that each AE occurred at the largest incremental local strain within the kinematically-defined hyperboloid, a unique AE location was established (location constrained by local strain). Given the large correlation between locations of large volumetric strain vs. deviatoric strain, AE locations were defined within the same pixel whether constrained by volumetric or deviatoric strain for $85 \%$ of the located AE. Where two or more AE had the same time-bin and the same kinematic constraint, we assumed that the largest AE would be correlated with the largest strain, effectively assigning AE locations sequentially from largest to lowest $\mathrm{AE}$ within a time-bin. Whilst the assumption of linking AE to the largest local strain should bias AE locations to be linked to larger local strains, the results showed that, effectively via proof by contradiction, the largest AEs do not occur at locations of large local strain, with the locations of large local strains being linked to small/moderate AE (Fig. 4). This observation, in turn, is evidence that deformation is primarily aseismic.

\section{Local incremental 3D strain fields from digital volume correlation between neighboring scans}

In addition to observing quasi-static fault development directly in the reconstructed $\mu \mathrm{CT}$ volumes, we quantified the full, incremental 3D strain tensor evolution using DVC between adjacent pairs of tomograms using the open-source software SPAM (50). The procedure involved computing linear displacement vectors between nodes (with 40 pixel spacing, equivalent to $316.4 \mu \mathrm{m}$ ) identified in the reference image and the same nodes identified in the deformed image by tracking a representative volume (window size 40 pixels) around the nodes. The transformation gradient tensor (local derivatives of displacement), F, was then computed using a Q8 shape function linking 8 neighbouring nodes, with F computed in the centre of the element. F was decomposed into the symmetric stretch tensor, $\mathbf{U}$, which was further decomposed into an isotropic and a deviatoric part. The volumetric strain (first invariant of the strain tensor showing dilation/compaction) was defined as the determinant of the transformation gradient tensor, $|\mathbf{F}|-1$. Here, we followed soil mechanics convention and defined 
dilation as positive volumetric strain and compaction as negative volumetric strain. The deviatoric strain (second invariant of the strain tensor showing shear deformation and referred to throughout as the shear strain) was defined as the Euclidean norm of the deviatoric part $\left\|\mathbf{U}_{d e v}\right\|$.

\section{Estimation of the overall seismic strain partition factor}

To estimate the seismic strain partition factor, we followed the approach of (3), who estimated the seismic moment of the largest observed AE event based on the largest observed fault, in order to scale the distribution of seismic moments from all their events. We used (51) to obtain the scalar seismic moments $M_{o}=C V \Delta \sigma$, with $C=16 / 7, V=r^{3}$ the crack volume and $\Delta \sigma$ the stress drop. The estimated maximum for the scalar seismic moment was $1.5 \mathrm{e}-3 \mathrm{Nm}$, using the Madariaga source model (52) with a radius, $r$, equal to one-half the maximum observed crack size $(2 r \sim 800 \mu \mathrm{m})$ and a stress drop of $1 \mathrm{MPa}$. The latter stress drop is an intermediate stress drop encompassing 23 different studies of natural, mining induced, and fracking induced seismicity and laboratory AE events (Supplementary Figure 13; 53, 54). The maxima of the AE envelopes were scaled to the maximum scalar seismic moment to obtain the scalar seismic moment distribution. The Kostrov (55) strain was estimated from

$$
\Delta \varepsilon_{i j}=\frac{1}{2 \mu \Delta V} \sum_{i=1}^{N} M_{i j} \text {, with } M_{i j}=\sqrt{2 M_{o} U_{i j}} \text { (56), where } U_{i j} \text { is the unit displacement tensor, } \mu \text { the shear }
$$
modulus and $\Delta V$ the total representative volume. Finally, the strain partition factor was estimated from

$$
\chi=\frac{\gamma_{A E}}{\gamma_{F}}(57,58,3), \text { with } \gamma_{A E} \text { representing the sum of scalar seismic moments multiplied by } \frac{\sqrt{2}}{2 \mu \Delta V}
$$

and $\gamma_{F}$ the average volumetric and deviatoric strains accumulated throughout the deformation experiment.

Estimation of bulk and local shear fracture energy 
The breakdown zone (slip-weakening) model (Fig. 5a; 23, 24) considers a fault as a shear crack with peak shear strength, $\tau_{\mathrm{P}}$. Relative slip on the fault, $\Delta \mathrm{u}$, initiates at $\tau_{\mathrm{P}}$ and then strength degrades from $\tau_{\mathrm{P}}$ to a constant residual frictional strength, $\tau_{\mathrm{F}}$, as $\Delta \mathrm{u}$ increases to a value $\Delta \mathrm{u}^{*}$, the critical slip-weakening distance, where tensile fracturing (mode I; dilation) transitions to frictional sliding (mode II; shear). This leads to a breakdown zone of dimension $\omega_{0}$ at the shear crack tip. $G_{c}$ for breakdown processes at the crack tip can be evaluated by integrating under the $\tau$ - $\Delta$ u curve (23; Fig. 5a). $\Delta u$ is resolved from the bulk inelastic axial displacement, $\Delta 1$, and depends on the angle, $\theta$, which the fault makes with the direction of loading. Shear stress depends on $\theta$ and the boundary stress conditions. Three main assumptions are involved: all axial strain beyond peak stress is accommodated by shear slip on the fault, the fault is sample-sized throughout, and $\omega_{0}$ is small compared with the size of the fault.

To obtain local geometric and strain information for the shear zone itself defined by the local strain fields that were output from the DVC (Fig. 3 and Supplementary Figure 4), we separated the shear zone core from other correlated strain clusters by thresholding above 0.004 strain. We then used a connected component object analysis to obtain the best-fitting ellipsoid for the shear zone at each strain increment, and hence obtained the angle $\theta$ of the shear zone with respect to the direction of loading (Supplementary Table 1) from the ellipsoid eigenvectors. The evolving shear zone object is shown in Supplementary Figure 9.

Following $(23,24)$, we then estimated $G_{c}=\int_{0}^{\Delta u *}\left[\tau(\Delta u)-\tau_{F}\right] d(\Delta u)$ for:

(i) Uniform slip on a sample-sized fault (as in 24) by first resolving relative slip, $\Delta \mathrm{u}$, from the bulk inelastic axial displacement, $\Delta \mathrm{l}$, and $\theta$ as follows: $\Delta \mathrm{u}=\Delta \mathrm{l} / \cos \theta$, and then calculating shear stress, $\tau=\left[\left(\sigma_{1}-\sigma_{3}\right) / 2\right] * \sin (2 \theta)$, from $\theta$ and the boundary stress conditions. A cubic fit was used to obtain an average bulk shear stress vs relative slip curve and we assumed that all axial shortening was caused by slip along the fault from $\tau_{\mathrm{P}}$. Axial shortening was corrected for elastic strain using the intact Young's modulus for the sample (Figs. 1c and 5a). 
(ii) Uniform slip at each $\mu \mathrm{CT}$ scan time, using the bulk shear strain and relative slip measurements at those times (rather than an average), in order to compare the uniform slip model directly with the observed local slip on the shear zone itself (estimated from the 3D strain fields). We assumed that all axial shortening was caused by slip along the fault from the point of final localization (scan c).

(iii)Total observed local slip on the shear zone itself from local dilation and shear strain. We assumed that slip started from the point of final localization (scan c) and used the bulk shear strain calculated in (ii). For the shear contribution to slip, we extracted the mean local incremental shear strain in the shear zone object, $\overline{\Delta \epsilon_{\text {shear }}}$, from the connected component object analysis described above. We corrected $\sum \overline{\Delta \epsilon_{\text {shear }}}$ for elastic strain using the intact shear modulus of the sample, obtained from the shear stress vs $\sum \overline{\Delta \epsilon_{\text {shear }}}$ curve (Supplementary Figure 8). Finally, we obtained local shear slip, $\Delta \mathrm{u}_{\text {shear, from an engineering strains }}$ approximation: $\Delta \mathrm{u}_{\text {shear }}=2 * \sum \overline{\Delta \epsilon_{\text {shear }}} *$ DVC node spacing (59). For the radial dilation contribution to slip, we extracted the mean local incremental radial dilation in the shear zone object, $\overline{\Delta \epsilon_{\mathrm{d} \text { lation }}}$, and corrected $\sum \overline{\Delta \epsilon_{\mathrm{d} \text { lation }}}$ for elastic radial strain using the elastic axial strain calculated above and an estimate of Poisson's ratio for Clashach sandstone (60). We then resolved the inelastic dilation onto the shear zone orientation, obtaining local dilational slip from an engineering strains approximation: $\Delta \mathrm{u}_{\text {dilation }}=\sum\left(\overline{\Delta \epsilon_{\text {dllatıon }}} / \sin \theta\right) *$ DVC node spacing.

\section{Acknowledgments}

We would like to thank the University of Edinburgh Geosciences Workshop for their support in developing the experimental apparatus, and Jonathan Singh for useful discussions about data file 
formats and estimation of acoustic waveform arrival times. We also acknowledge Diamond Light

Source for time on beamline I12-JEEP under proposal MG22517. This work is supported by the UK's

Natural Environment Research Council (NERC) through the CATFAIL project NE/R001693/1

Catastrophic failure: what controls precursory localisation in rocks?

\section{Author contributions}

Conceptualization (A. Bell, I. Butler, A. Cartwright-Taylor, A. Curtis, F. Fusseis, I. Main), data curation (A. Cartwright-Taylor, M. Mangriotis), formal analysis (A. Cartwright-Taylor, M. Mangriotis, E. Andò, A. Bell, A. Crippen), funding acquisition (A. Bell, I. Butler, A. Cartwright-Taylor, A. Curtis, F. Fusseis, I. Main), investigation (I. Butler, A. Cartwright-Taylor, F. Fusseis, D. Leung, O. V. Magdysyuk, S. Marti, R. Rizzo), methodology (E. Andò, M. Ling), project administration (A. Cartwright-Taylor, I. Main), resources (I. Butler, E. Andò, M. Ling, O. V. Magdysyuk), software (E. Andò, M. Ling), supervision (I. Main, A. Curtis, A Bell, I. Butler, F. Fusseis), validation (A. Cartwright-Taylor, M. Mangriotis, I. Main, A. Curtis.), writing - original draft (A. Cartwright-Taylor, M. Mangriotis, I. Main, M. Ling), writing - review and editing (A. Bell, I. Butler, A. Curtis, F. Fusseis, O. V. Magdysyuk, R. Rizzo).

\section{Statement of competing interests}

The authors declare no competing interests.

\section{Data and materials availability}

The data supporting our conclusions can be found in main text, in the supplementary information, and in the $\mu \mathrm{CT}$ data sets held at the NERC repository (link tbc). When using the $\mu \mathrm{CT}$ data sets, please cite

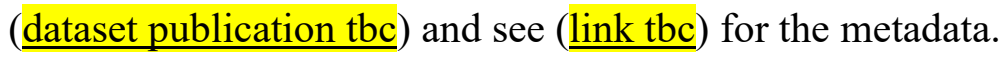




\section{References}

1. D. Lockner, J. D. Byerlee, V. Kuksenko, A. Ponomarev, A. Sidorin, Quasi-static fault growth and shear fracture energy in granite. Nature 350 39-42 (1991).

2. I. Main, A damage mechanics model for power-law creep and earthquake aftershock and foreshock sequences. Geophys. J. Int. 142, 151-161 (2000).

3. G. Dresen, G. Kwiatek, T. Goebel, Y. Ben-Zion, Seismic and aseismic preparatory processes before large stick-slip failure. Pure Appl. Geophys. 177, 5741-5760 (2020).

4. S. Bourne, S. J. Oates, J. van Elk, D. Doornhof, A seismological model for earthquakes induced by fluid extraction from a subsurface reservoir. J. Geophys. Res. 119, 8991-9015 (2014).

5. P. R. Sammonds, P. G. Meredith, I. G. Main, Role of pore fluids in the generation of seismic precursors to shear fracture. Nature 359, 228-230 (1992).

6. C. C. Graham, S. Stanchits, I. G. Main, G. Dresen, Comparison of polarity and moment tensor inversion methods for source analysis of acoustic emission data. lnt. J. Rock Mech. Min. Sci. 47, 161-169 (2010).

7. N. Cho, C. D. Martin, D. S. Sego, A clumped particle model for rock. lnt. J. Rock Mech. Min. Sci. 44(7), 997-1010 (2007).

8. D. O. Potyondy, P. A. Cundall, A bonded particle model for rock. Int. J. Rock Mech. Min. Sci. 41(8), 1329-1364 (2004).

9. C. G. Sammis, M. F. Ashby, The failure of brittle porous solids under compressive stress states. Acta Metall. 34, 511-526 (1986).

10. M. F. Ashby, S. D. Hallam, The failure of brittle solids containing small cracks under compressive stress states. Acta Metall. 34, 497-510 (1986). 
11. H. Hori, S. Nemat-Nasser, Compression-induced microcrack growth in brittle solids: axial splitting and shear failure. J. Geophys. Res. 90(B4), 3105-3125 (1985).

12. J. Vasseur, F. B. Wadsworth, Y. Lavallée, A. Bell, I. G. Main, D. B. Dingwell, Heterogeneity: The key to failure forecasting. Sci. Rep. 5, 13259 (2015).

13. D. Lockner, J. D. Byerlee, V. Kuksenko, A. Ponomarev, A., Sidorin, “Observations of quasi-static fault growth from acoustic emissions" in Fault Mechanics and Transport Properties of Rocks, B. Evans, T.-F. Wong, Eds. (Academic Press, 1992), vol. 51, chap. 1, pp. 3-31.

14. M. Terada, T. Yanagidani, S. Ehara, "AE rate controlled compression test of rocks" in 3rd Conf. on Acoustic Emission / Microseismic Activity in Geologic Structures and Materials, H. R. Hardy, F. W. Leighton, Eds. (Trans Tech, 1984), pp. 159-171.

15. L. Huang, P. Baud, B. Cordonnier, F. Renard, L. Liu, T.-F. Wong, Synchrotron X-ray imaging in 4D: multiscale failure and compaction localization in triaxially compressed porous limestone. Earth Planet. Sci. Lett. 528, 115831 (2019).

16. J. McBeck, Y. Ben-Zion, F. Renard, The mixology of precursory strain partitioning approaching brittle failure in rocks. Geophys. J. Int. 221, 1856-1872 (2020).

17. A. Cartwright-Taylor, I. G. Main, I. B. Butler, F. Fusseis, M. Flynn, A. King, Catastrophic failure: how and when? Insights from 4-D in situ X-ray microtomography. J. Geophys. Res. Solid Earth 125, e2020JB019642 (2020).

18. M. Drakopoulos, T. Connolley, C. Reinhard, R. Atwood, O. Magdysyuk, N. Vo, M. Hart, L. Connor, B. Humphreys, G. Howell, S. Davies, T. Hill, G. Wilkin, U. Pedersen, A. Foster, N. De Maio, M. Basham, F. Yuan, K. Wanelik, I12: the Joint Engineering, Environment and Processing (JEEP) beamline at Diamond Light Source. J. Synchrotron Rad. 22, 828-838 (2015). 
19. I. O. Ojala, I. G. Main, B. T. Ngwenya, Strain rate and temperature dependence of Omori law scaling constants of AE data: implications for earthquake foreshock-aftershock sequences. Geophys. Res. Lett. 31, L24617 (2004).

20. F. Renard, J. McBeck, B. Cordonnier, X. Zheng, N. Kandula, J. R. Sanchez, M. Kobchenko, C. Noiriel, W. Zhu, P. Meakin, F. Fussies, D. K. Dysthe, Dynamic in situ three-dimensional imaging and digital volume correlation analysis to quantify strain localization and fracture coalescence in sandstone. Pure Appl. Geophys. 176, 1083-1115 (2018).

21. F. Renard, J. McBeck, N. Kandula, B. Cordonnier, P. Meakin, Y. Ben-Zion, Volumetric and shear processes in crystalline rock approaching faulting. Proc. Natl. Acad. Sci. 116, 16234-16239 (2019).

22. S. Lennartz-Sassinek, I.G. Main, M. Zaiser, C. Graham, Acceleration and localization of subcritical crack growth in a natural composite material. Phys. Rev. E 90, 052401 (2014).

23. J. R. Rice, "The mechanics of earthquake rupture" in Physics of the Earth's Interior, A. M. Dziewonski, E. Boschi, Eds. (Italian Phys. Soc. 1980), pp. 555-649.

24. T.-F. Wong, Shear fracture energy of Westerly granite from post-failure behaviour. J. Geophys. Res. 87, 990-1000 (1982).

25. F. M. Aben, N. Brantut, T. M. Mitchell, E. C. David, Rupture energetics in crustal rock from laboratory-scale seismic tomography. Geophys. Res. Lett. 46, 7337-7344.

26. G. I. Barenblatt, The mathematical theory of equilibrium cracks in brittle fracture. Adv. Appl. Mech. 7, 55-129 (1962).

27. S. Roy, S. Biswas, Size distribution of emitted energies in local load sharing fiber bundles. Front. Phys. 9, 643602 (2021).

28. D. R. Faulkner, T. M. Mitchell, D. Healy, M. J. Heap, Slip on 'weak' faults by the rotation of regional stress in the fracture damage zone. Nature 444, 922-925 (2006). 
29. Z. E. Ross, B. Idini, Z. Jia, O. L. Stephenson, M. Zhong, X. Wang, Z. Zhan, M. Simons, E. J. Fielding, S.-H. Yun, E. Hauksson, A. W. Moore, Z. Liu, J. Jung, Hierarchical interlocked orthogonal faulting in the 2019 Ridgecrest earthquake sequence. Science 366, 346-351 (2019).

30. T. Taymaz, J. Jackson and D. McKenzie, Active tectonics of the north and central Aegean Sea. Geophys. J. Int. 106, 433-490 (1991).

31. H. Schouten, K. D. Klitgord, D. G. Gallo, Edge-driven microplate kinematics. J. Geophys. Res. 98, 6689-6701 (1993).

32. A. Glerum, S. Brune, D. S. Stamps, M. R. Strecker, Victoria continental microplate dynamics controlled by the lithospheric strength distribution of the East African Rift. Nat. Comm. 11, 2881 (2020).

33. G. Duclaux, R. S. Huismans, D. A. May, Rotation, narrowing, and preferential reactivation of brittle structures during oblique rifting. Earth Planet. Sci. Lett. 531, 115952 (2020).

34. R. E. Rizzo, D. Healy, M. J. Heap, N. J. Farrell, Detecting the onset of strain localization using two-dimensional wavelet analysis on sandstone deformed at different effective pressures. $J$. Geophys. Res. Solid Earth 123, 10460-10478 (2018).

35. G. Corti, R. Cioni, Z. Franceschini, F. Sani, S. Scaillet, P. Molin, I. Isola, F. Mazzarini, S. Brune, D. Keir, A. Erbello, A. Muluneh, F. Illsley-Kemp, A. Glerum. Aborted propagation of the Ethiopian rift caused by linkage with the Kenyan rift. Nat. Comm. 10, 1309 (2019).

36. R. K. Davies, D. D. Pollard, Relations between left-lateral strike-slip faults and right-lateral monoclinal kink bands in granodiorite, Mt. Abbot Quadrangle, Sierra Nevada, California. Pure Appl. Geophys. 124, 177-201 (1986).

37. T. M. Mitchell, D. R. Faulkner, Towards quantifying the matrix permeability of fault damage zones in low porosity rocks. Earth Planet. Sci. Lett. 339-340, 24-31 (2012). 
38. N. J. C. Farrell, D. Healy, Anisotropic pore fabrics in faulted porous sandstones. J. Struct. Geol. 104, 125-141 (2017).

39. I. B. Butler, F. Fusseis, A. Cartwright-Taylor, M. Flynn, Mjölnir: a miniature triaxial rock deformation apparatus for 4D synchrotron x-ray micro-tomography. J. Synchrotron Rad. 27, 16811687 (2020).

40. N. Wadeson, M. Basham, Savu: a Python-based, MPI framework for simultaneous processing of multiple, N-dimensional, large tomography datasets. arXiv:1610.08015 (2016).

41. N. T. Vo, M. Drakopoulos, R. C. Atwood, C. Reinhard, Reliable method for calculating the center of rotation in parallel-beam tomography. Opt. Express 22, 19078-19086 (2014).

42. N. T. Vo, M. Drakopoulos, R. C. Atwood, Superior techniques for eliminating ring artifacts in Xray micro-tomography. Opt. Express 26, 28396-28412 (2018).

43. N. T. Vo, R. C. Atwood, M. Drakopoulos, Radial lens distortion correction with sub-pixel accuracy for X-ray micro-tomography. Opt. Express 23, 32859-32868 (2015).

44. D. Paganin, S. C. Mayo, T. E. Gureyev, P. R. Miller, S. W. Wilkins, Simultaneous phase and amplitude extraction from a single defocused image of a homogeneous object. J. Microsc. 206, 3340 (2002).

45. D. Pelt, D. Gürsoy, W. J. Palenstijn, J. Sijbers, F. De Carlo, K. J. Batenburg, Integration of tomopy and the astra toolbox for advanced processing and reconstruction of tomographic synchrotron data. J. Synchrotron Rad. 23, 842-849 (2016).

46. W. van Aarle, W. J. Palenstijn, J. De Beenhouwer, T. Altantzis, S. Bals, K. J. Batenburg, J. Sijbers, The ASTRA toolbox: a platform for advanced algorithm development in electron tomography. Ultramicroscopy 157, 35-47 (2015). 
47. W. van Aarle, W. J. Palenstijn, J. Cant, E. Janssens, F. Bleichrodt, A. Dabravolski, J. De Beenhouwer, K. J. Batenburg, J. Sijbers, Fast and flexible x-ray tomography using the ASTRA toolbox. Opt. Express 24, 25129-25147 (2016).

48. W. J. Palenstijn, K. J. Batenburg, J. Sijbers, Performance improvements for iterative electron tomography reconstruction using graphics processing units (GPUs). J. Struct. Biol. 176, 250-253 (2011).

49. F. Birch, The velocity of compressional waves in rocks to 10 kilobars, part 1. J. Geophys. Res. $\mathbf{6 5}$, 1083-1102 (1960).

50. O. Stamati, E. Andò, E. Roubin, R. Cailletaud, M. Wiebicke, G. Pinzon, C. Couture, R. C. Hurley, R. Caulk, D. Caillerie, T. Matsushima, P. Bésuelle, F. Bertoni, T. Arnaud, A. O. Laborin, R. Rorato, Y. Sun, A. Tengattini, O. Okubadejo, J.-B. Colliat, M. Saadatfar, F. E. Garcia, C. Papazoglou, I. Vego, S. Brisard, J. Dijkstra, G. Birmpilis, SPAM: software for practical analysis of materials. J. Open Source Softw. 5(51), 2286 (2020). https://ttk.gricad-pages.univ-grenoblealpes.fr/spam/index.html.

51. H. Kanamori, D. L. Anderson, Theoretical basis of some empirical relations in seismology. Bull. Seismol. Soc. Am. 65, 1073-1095 (1975).

52. R. Madariaga, Dynamics of an expanding circular fault, Bull. Seismol. Soc. Am. 66(3), 639-666 (1976).

53. A. B. Blanke, G. Kwiatek, T. H. W. Goebel, M. Bohnhoff, G. Dresen, Stress drop-magnitude dependence of acoustic emissions during laboratory stick-slip. Geophys. J. Int. 224, 1371-1380 (2021). 
54. G. Kwiatek, K. Plenkers, G. Dresen, JAGUARS Research Group, Source parameters of picoseismicity recorded at Mponeng Deep Gold Mine, South Africa: implications for scaling relations, Bull. Seismol. Soc. Am. 101(6), 2592-2608 (2011).

55. V. Kostrov, Seismic moment and energy of earthquakes and seismic flow of rock. Earth Phys. 1, 23-40 (1974).

56. P. G. Silver, T. H. Jordan, Optimal estimation of scalar seismic moment. Geophys. J. Int. 70(3), $755-787$ (1982).

57. C. H. Scholz, J. Campos, The seismic coupling of subduction zones revisited. J. Geophys. Res. 117, B05310 (2012).

58. G. C. McLaskey, D. A. Lockner, Preslip and cascade processes initiating laboratory stick slip. J. Geophys. Res. 119, 6323-6336 (2014).

59. https://www.continuummechanics.org/strain.html accessed 22 March 2021

60. M. H. Lamorde, "Development and application of a novel approach to sand production prediction", thesis, Heriot-Watt University (2015).

\section{Supplementary Information}

Supplementary Note: Feedback control of deformation

Supplementary Figures 1-14

Supplementary Tables 1-2

Supplementary Movies 1-8 

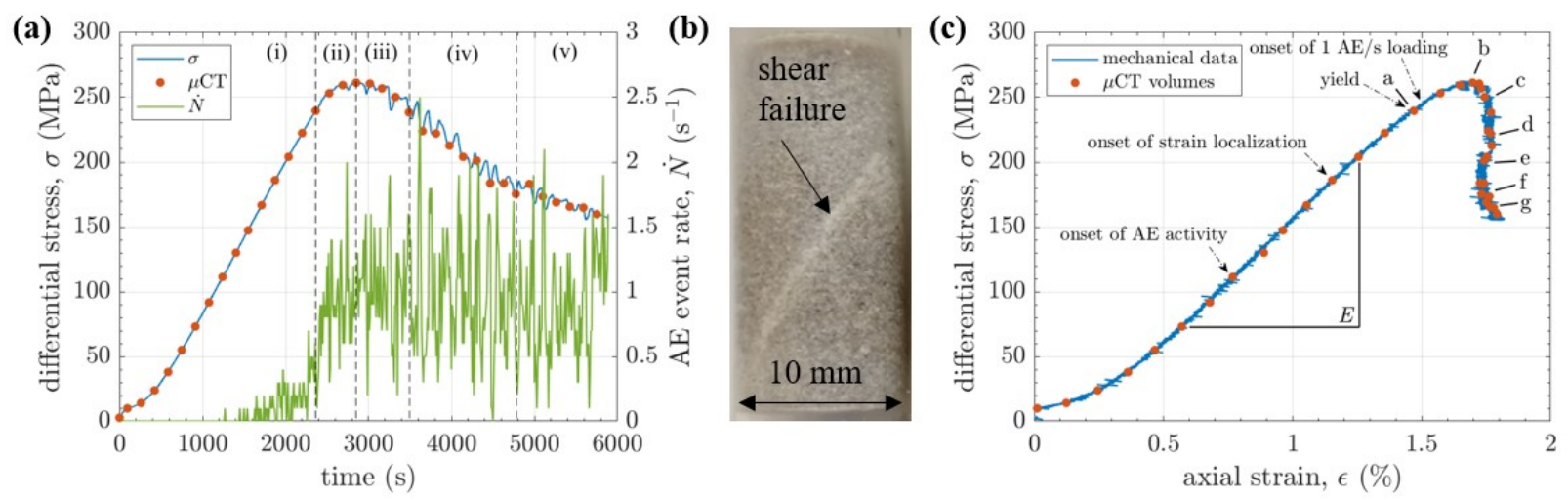

Fig. 1. Bulk mechanical behaviour of Clashach sandstone. (a) Differential stress and AE event rate evolution with time. The transition from constant strain rate loading $\left(10^{-5} / \mathrm{s}\right)$ to constant $\mathrm{AE}$ event rate loading (1 AE/s) occurred early in stage (ii). During stage (iv), shear zone propagation occurs first across the sample, and then down the sample. (b) Photograph of the failed sample showing the localised shear damage zone. (b) Differential stress plotted against axial strain. Letters a-g refer to the image labels in Figs. 2 and 3. Young's modulus, $E=19.369 \pm 0.028 \mathrm{GPa}$, was calculated over the range shown. AE activity began at $40 \%$ of peak stress, $\sigma_{\mathrm{P}}$, with sample yield at $0.85 \sigma_{\mathrm{P}}$. The $\mathrm{AE}$ feedback control $(1 \mathrm{AE} / \mathrm{s})$ modulated the strain rate from $0.93 \sigma_{\mathrm{P}}$. 

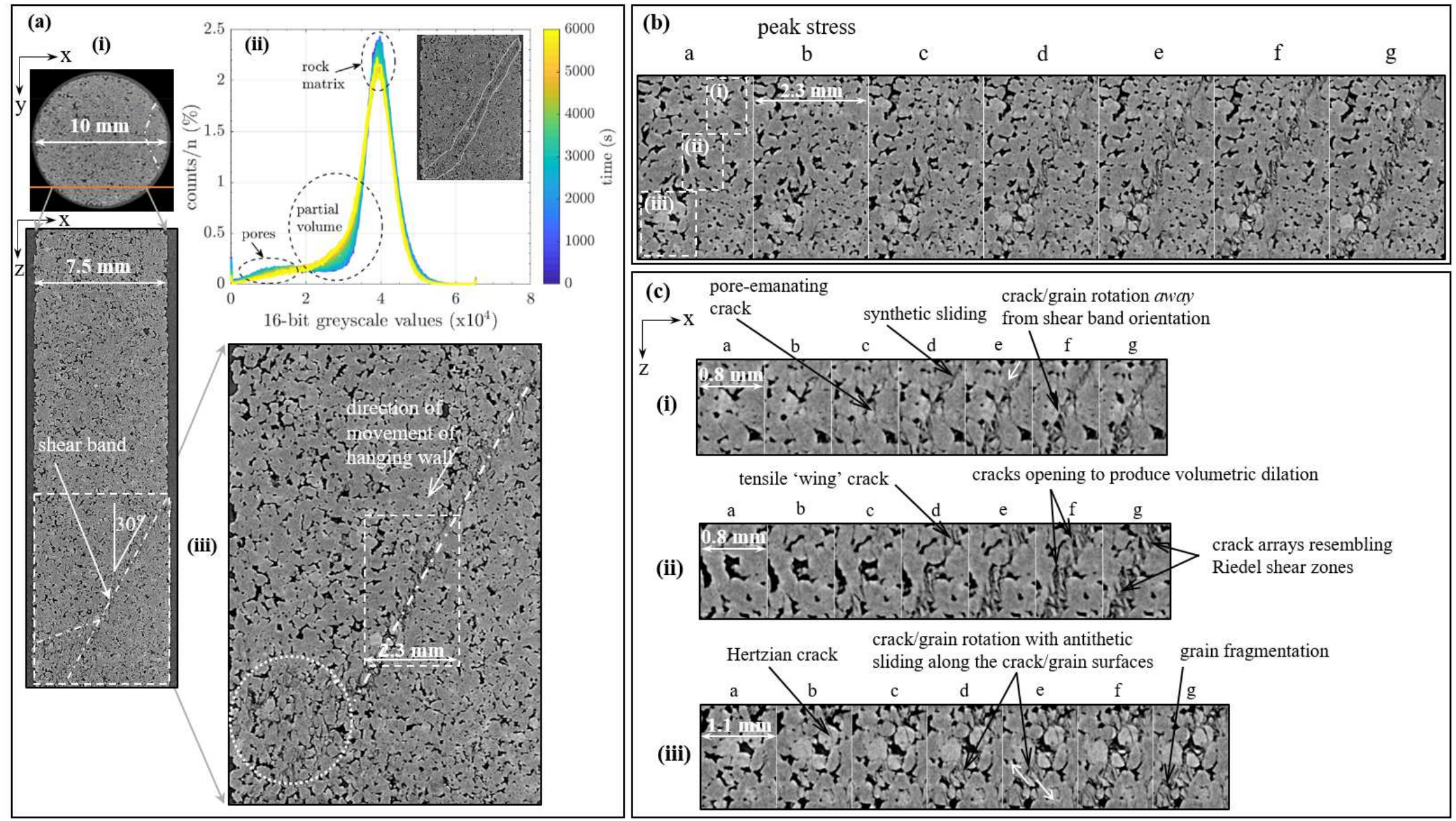

Fig. 2. Micro-scale damage evolution close to and following peak stress. (a-i) Reconstructed 2D $\mu C T$ slice (x,y-oriented, where $\mathrm{x}$ and $\mathrm{y}$ are perpendicular to each other and to the direction of loading, and $\mathrm{x}$ is across-strike and $\mathrm{y}$ is along-strike of the shear zone) showing 
the plane (orange line) of a re-slice of the original $\mu \mathrm{CT}$ volume (x,z-oriented, where $\mathrm{z}$ is the direction of loading) where the shear zone initially localised. The corresponding across-strike (x,z-oriented) re-slice is shown between the grey arrows with the shear zone highlighted by dash-dot lines. (a-ii) histogram of greyscale x-ray intensity values (a proxy for density) showing evolution within the shear zone region (white line in inset image) and an increasing number of partial volume voxels representing increasing damage in the shear zone. (a-iii) Zoomed-in view (region between the grey arrows) of the x,z-oriented slice in (A-i) highlighting the narrow shear zone (dash-dot line) formed after peak stress, and the region of damage that formed after yield but before peak stress (dotted circle).

(b) Further zoomed-in view of the across-strike slices (x,z-oriented) showing shear zone emergence and development in region shown by dashed box in (a-iii) for scans a-g (see also Figs. 1c and 3). (c) Even further zoomed-in slices (x,z-oriented) highlighting the variety of micro-mechanisms involved in shear zone formation: numbers (i)-(iii) correspond to the dashed boxes in (b; slice a). When the whole time-series is viewed as an animation (Supplementary Movies 1 and 2), the micro-mechanisms illustrated by the annotations are apparent. 
(a)
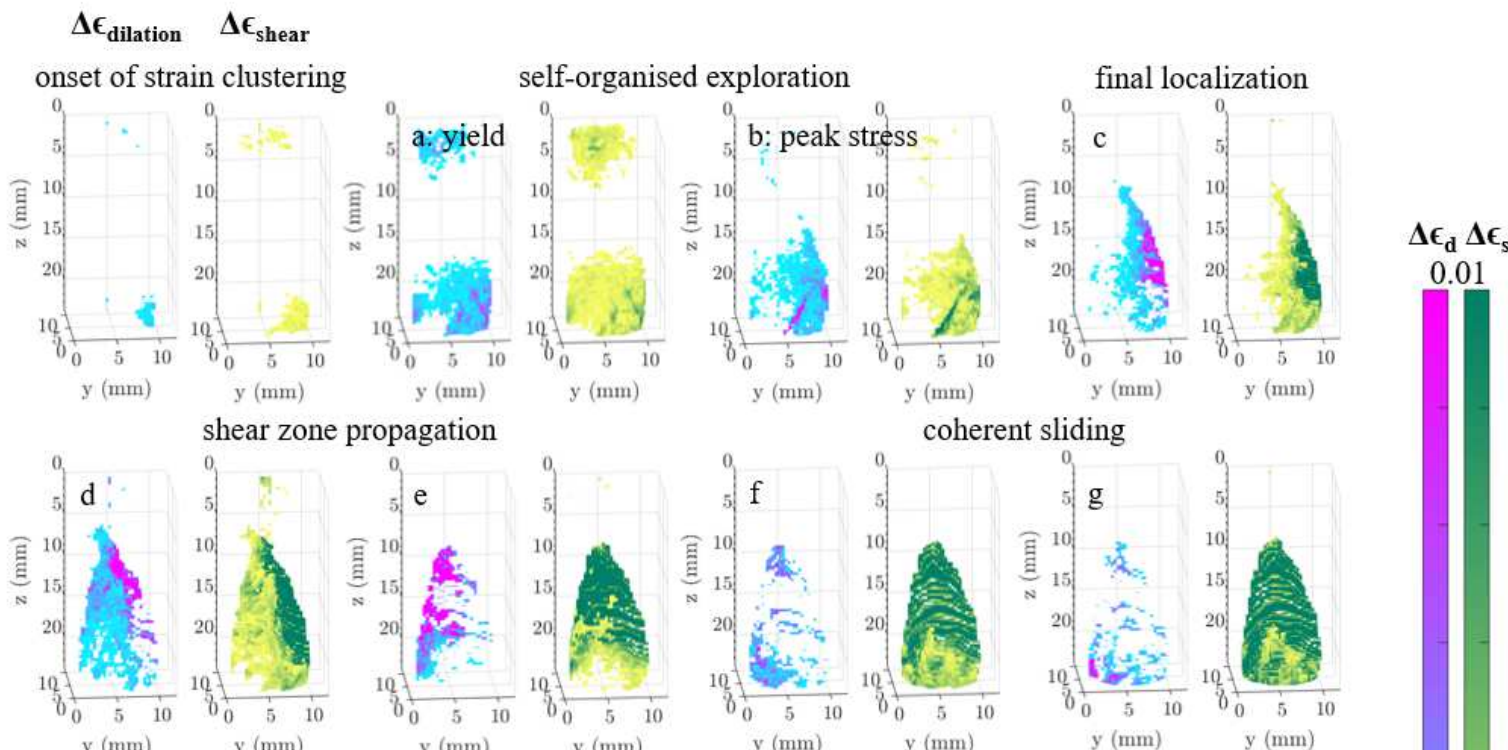

(b)
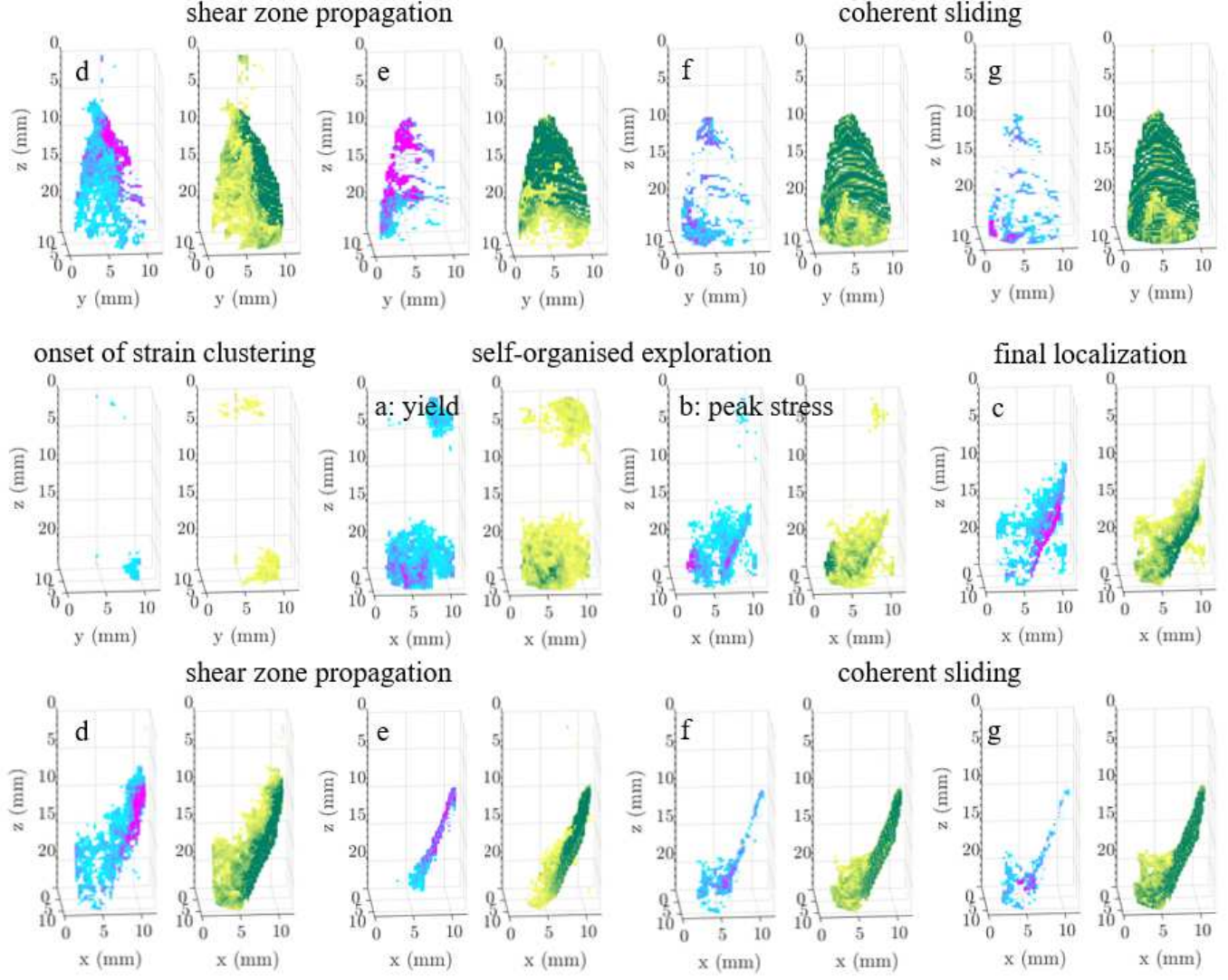

Fig. 3. 3D incremental strain fields from the onset of strain localisation (marked in Fig. 1c).

Incremental dilation, $\Delta \epsilon_{\mathrm{d}}$ (blue-pink) and shear strain, $\Delta \epsilon_{\mathrm{s}}$ (yellow-green) were calculated from 
$652 \Delta \epsilon_{\mathrm{S}}$ and $\Delta \epsilon_{\mathrm{d}}$ were $\sim 0.04$; Supplementary Figures S4 and S5). The thresholds were chosen to 653 visually highlight regions of localised strain. Letters a-g correspond to those in Figs. 1c and 2, 654 with the strain increment following the scan. Strain localisation began at $0.7 \sigma_{P}$. 
(a)

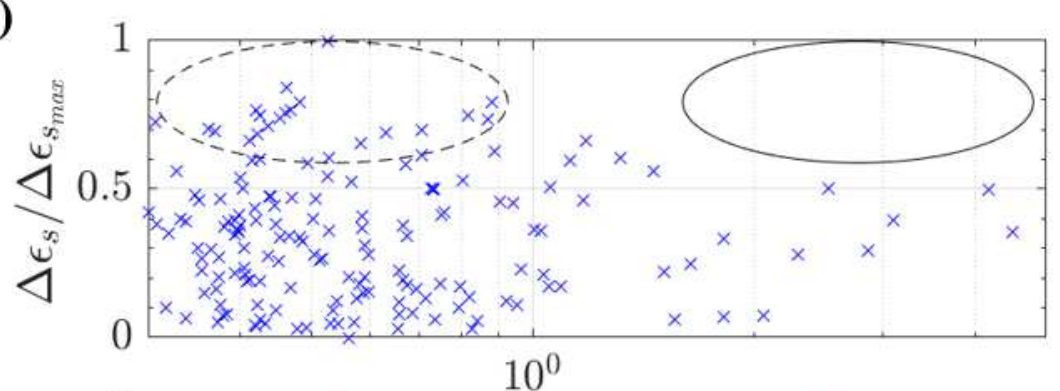

(b)

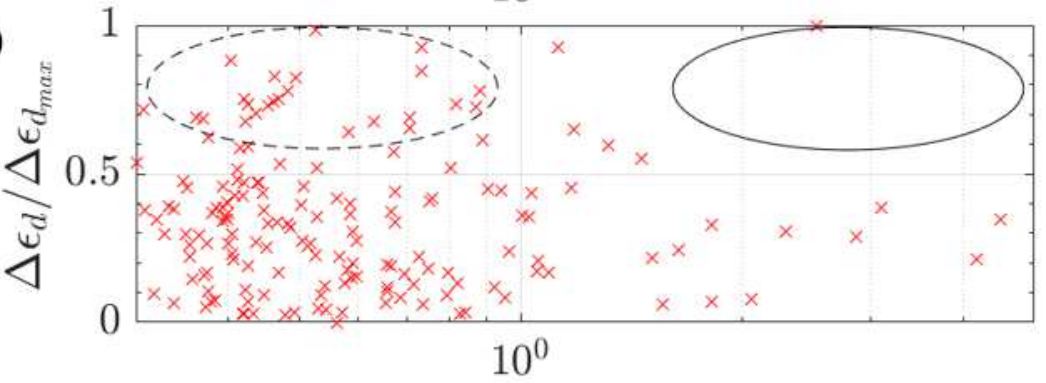

AE amplitude (arbitrary units)

Fig. 4. Relationship between AE amplitude (in log-scale) and local incremental strain at the AE 


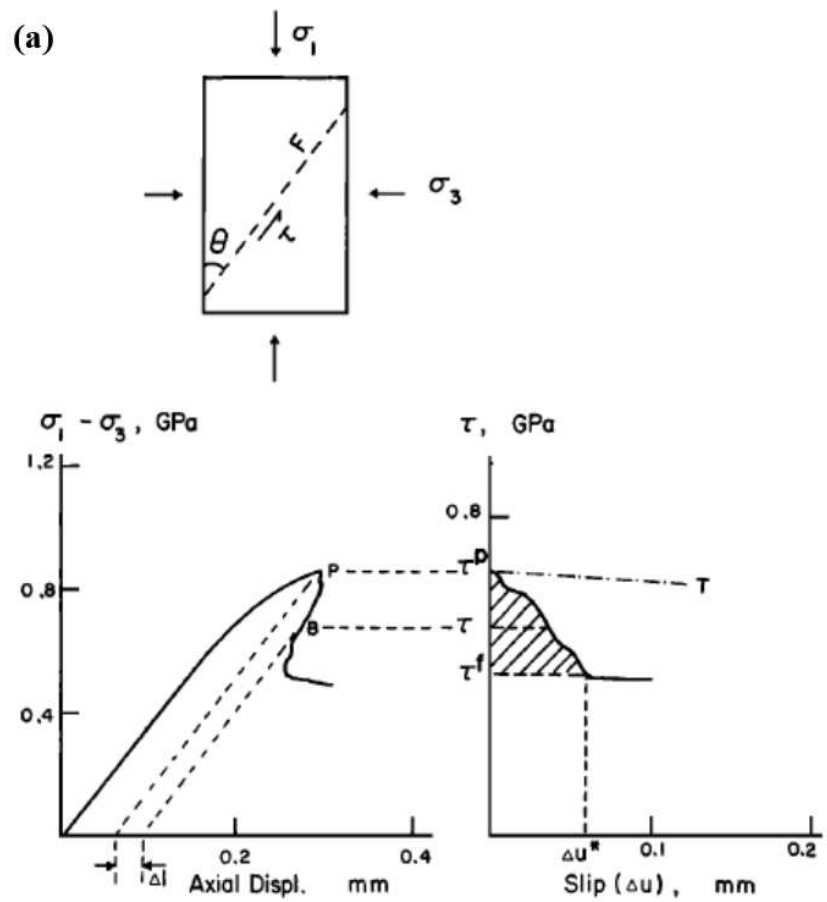

664

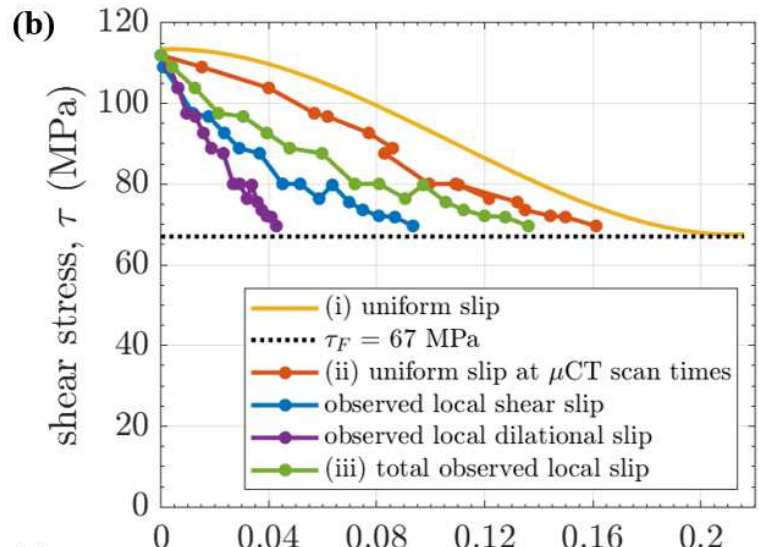

(c)

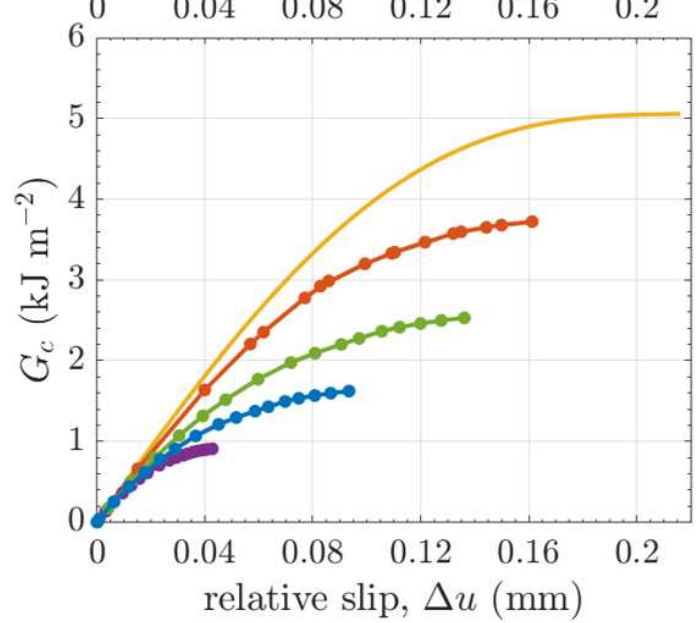

Fig. 5. Shear fracture energy estimated from bulk strain and from local incremental strain in the shear zone. (a) Procedure for estimating $G_{c}$ from shear stress and inelastic axial displacement resolved on the fault (reproduced from Fig. 1 in 24) showing (top) schematic of sample with boundary stresses $\sigma_{1}$ (axial) and $\sigma_{3}$ (radial), the angle $\theta$ that fault $\mathrm{F}$ makes with $\sigma_{1}$, and the shear stress $\tau$ acting on the fault; (bottom left) obtaining inelastic axial displacement $\Delta \mathrm{l}$ from the differential stress vs axial displacement curve and then resolving it onto $\mathrm{F}$ to obtain the relative slip $\Delta \mathrm{u}$; and (bottom right) obtaining $\mathrm{G}_{\mathrm{c}}$ by integration under $\tau-\Delta \mathrm{u}$ curve from peak shear stress $\tau_{\mathrm{P}}$ to residual frictional strength $\tau_{\mathrm{F} .}$ (b) Relationship between $\tau$ and $\Delta \mathrm{u}$ for $\theta=30.3^{\circ}$ (Supplementary Table 1) for (i) yellow; uniform slip from average bulk axial stress and strain data, (ii) orange; uniform slip from bulk axial stress and strain data at each $\mu \mathrm{CT}$ scan time, and 
675 (iii) green; total observed local slip in the developing shear zone, obtained from direct dilation 676 and shear strain measurements. We obtained $\mathrm{G}_{\mathrm{c}}$ by integration under the $\tau$ - $\Delta \mathrm{u}$ curve from peak $\tau$ 677 to $\tau_{\mathrm{F}}$ (dotted black line). The contributions to (iii) from local shear strain (blue) and local dilation 678 (purple) are also shown. (C) Evolution of $\mathrm{G}_{\mathrm{c}}$ calculated from (B) as $\Delta \mathrm{u}$ increases. 


\section{Supplementary Files}

This is a list of supplementary files associated with this preprint. Click to download.

- supplementarymovie1.mp4

- supplementarymovie2.mp4

- supplementarymovie3.mp4

- supplementarymovie4.mp4

- supplementarymovie5.mp4

- supplementarymovie6.mp4

- supplementarymovie7.mp4

- cartwrighttayloretalsupplementaryinformation.pdf

- supplementarymovie8.mp4 